\title{
Pengembangan Asesmen Literasi Kimia pada Materi Hukum-Hukum Dasar Kimia dan Stoikiometri
}

\section{Development of Chemical Literacy Assessment on Fundamental Chemical Laws and Stoichiometry}

\author{
A Y M Sartika ${ }^{1}$ and E Yusmaita ${ }^{*}$ \\ 1 Pendidikan Kimia, Universitas Negeri Padang, Jl. Prof. Dr. Hamka, Air Tawar Barat, \\ Padang Utara, Sumatera Barat, Indonesia 25171 \\ *ekayusmaita@fmipa.unp.ac.id
}

\section{ARTICLE INFO}

Received 09 June 2020

Revised 28 June 2020

Published 03 July 2020

\begin{abstract}
This chemistry literacy assessment instrument developed because of recent challenge toward student learning achievement evaluation so it could not only grade student's cognitive ability in term of understanding and memorizing, but also will grade the application of students' concept to face any problems. The availability of the chemistry literacy assessment instrument consists of various aspects, such as content, context, High Order Learning Skills (HOLS), and attitude. These aspects are expected to answer those challenges. This study aims to produce a proper and right chemistry literacy assessment toward fundamental law of chemistry and stoichiometry topic based on content validity value and questions numbers, reliability grade, difficulty level and chemistry literacy question differentiator level. This study is the development type, which is Model of Educational Reconstruction (MER) design. The clarification of a test instrument on empirical study was done toward three chemistry and education experts (lecturer and teacher). The instrument used was chemistry literacy question which consists of seven discourse question, then expanded into 15 questions. The result showed that content validity value of the designed chemistry literacy assessment could be categorized as valid.
\end{abstract}

\section{KEYWORDS}

Chemical Literacy, Fundamental Chemical Laws,

Model of Educational Reconstruction (MER), Stoichiometry

\begin{abstract}
ABSTRAK
Instrumen penilaian literasi kimia dikembangkan karena tantangan saat ini terhadap evaluasi prestasi belajar peserta didik tidak hanya menilai kognitif pada bagian pemahaman serta hafalan saja, tetapi diharapkan dapat menilai penerapan konsep peserta didik dalam menghadapi suatu permasalahan. Tersedianya instrumen penilaian literasi kimia yang terdiri atas aspek konten, konteks, High Order Learning Skills (HOLS), dan sikap diharapkan mampu menjadi jawaban dari tantangan tersebut. Tujuan penelitian ini adalah untuk menghasilkan asesmen literasi kimia pada materi hukum-hukum dasar kimia dan stoikiometri yang baik dan benar berdasarkan nilai validitas konten (isi) dan item butir soal, nilai reliabilitas, tingkat kesukaran, dan daya pembeda soal literasi kimia. Jenis penelitian yang digunakan adalah pengembangan dengan menggunakan desain Model of Educational Reconstruction (MER). Tahapan klarifikasi instrumen tes pada studi empiris dilakukan kepada 3 orang pakar kimia dan pendidikan (dosen dan guru). Instrumen yang digunakan berupa soal literasi kimia yang terdiri atas 7 wacana soal yang dijabarkan menjadi 15 butir item soal. Hasil penelitian menunjukkan bahwa nilai validitas konten (isi) asesmen literasi kimia yang dirancang dikategorikan "valid".
\end{abstract}

\section{KATA KUNCI}

Hukum-Hukum Dasar Kimia, Literasi Kimia,

Model of Educational Reconstruction (MER), Stoikiometri 


\section{PENDAHULUAN}

Asesmen atau penilaian dapat diartikan sebagai proses untuk mendapatkan informasi yang digunakan sebagai dasar pengambilan keputusan yang terkait dengan kemampuan dan daya serap materi pembelajaran peserta didik ${ }^{[1]}$. Asesmen penting dilakukan karena hasilnya digunakan untuk menyelidiki tingkat pemahaman peserta didik mengenai konsep-konsep. Asesmen berfungsi sebagai alat untuk menilai kemampuan peserta didik mengenai hubungan antara konsep, merencanakan proses pembelajaran, menentukan tingkat/ urutan, menentukan pembelajaran tingkat lanjut, pengembangan teori pembelajaran, merumuskan kebijakan, dan mengevaluasi kurikulum ${ }^{[2]}$. Oleh karena itu, perlunya merencanakan, melaksanakan, dan menganalisis asesmen dengan baik sehingga dapat berfungsi sebagaimana mestinya.

Tujuan utama dikembangkannya literasi sains agar peserta didik memiliki kemampuan dalam memahami permasalahan dan mampu mengambil keputusan ketika ada permasalahan yang berkaitan dengan sains dan teknologi ${ }^{[3]}$. Instrumen penilaian literasi kimia dikembangkan karena tantangan saat ini terhadap evaluasi prestasi belajar peserta didik tidak hanya menilai kognitif pada bagian pemahaman serta hafalan saja, tetapi diharapkan dapat menilai penerapan konsep peserta didik dalam menghadapi suatu permasalahan.

Literasi kimia merupakan bagian dari literasi sains. Literasi kimia terdiri dari beberapa komponen diantaranya: memahami sifat kimia, norma-norma, metode-metode, memahami teori, konsep dan model kimia, memahami bagaimana sains dan teknologi berbasis kimia yang saling berhubungan satu sama lain karena sains berusaha menghasilkan penjelasan tentang alam sedangkan teknologi kimia berusaha untuk mengubah dunia itu sendiri, memahami sifat dari fenomena kimia yang berlaku sehingga menghasilkan perubahan atau variasi pada fenomena/situasi yang lebih baik, menghargai dampak ilmu kimia, dan teknologi kimia yang terkait dengan masyarakat ${ }^{[4]}$. Peserta didik yang memiliki literasi kimia diharapkan dapat mengaplikasikan konsep kimia untuk menjelaskan fenomena yang terjadi di sekitarnya secara ilmiah dan mengaplikasikan fenomena serta mampu menyeimbangkan antara perkembangan ilmu pengetahuan dan dampaknya terhadap lingkungan. Sikap peduli dan sadar lingkungan tercermin dalam pribadi peserta didik yang memiliki literasi kimia ${ }^{[5]}$.

Programme for International Student Assessment (PISA) merupakan salah satu bentuk program penilaian tingkat internasional yang dilakukan oleh lembaga Organization for Economic Co-operation and Development (OECD) yang mengukur prestasi literasi peserta didik salah satunya literasi sains $\mathbf{s}^{[6]}$. Tingkat literasi peserta didik Indonesia yang diukur melalui studi PISA masih terbilang memprihatinkan. Berdasarkan hasil survei tahun terakhir PISA pada tahun 2018 menunjukkan peringkat Indonesia berada pada peringkat 70 dari 78 negara dengan skor yang diperoleh $396^{[7]}$. Salah satu faktor penyebabnya adalah peserta didik di Indonesia belum terbiasa dan belum terlatih dalam menjawab soal berbasis literasi sains ${ }^{[8]}$. Fakta tersebut secara garis besar merupakan gambaran pembelajaran sains di Indonesia yang masih perlu mendapat perhatian secara khusus dan mendalam.

Asesmen literasi kimia dirancang berdasarkan aspek konten, konteks, keterampilan belajar tingkat tinggi, dan sikap yang mengacu pada domain literasi kimia sedangkan rancangan rubrik penilaian jawaban didasarkan pada tingkat level literasi sains ${ }^{[5]}$. Tingkatan level tersebut adalah scientific illiteracy, siswa tidak dapat menjawab soal atau jawaban yang diberikan salah; nominal scientific literacy, yaitu siswa menjawab secara singkat dan adanya miskonsepsi; functional scientific literacy, siswa dapat menjawab namun pemahamannya masih sangat terbatas; conceptual scientific literacy, siswa menjawab dengan lengkap dan sudah bisa menghubungkan dengan konsep yang dipelajarinya; serta multidimensional scientific literacy yaitu siswa mampu menjawab lebih luas lagi serta dapat menghubungkan pemahamannya dengan ilmu lainnya ${ }^{[9]}$. Oleh karena itu, diperlukan suatu gagasan yang mendasar dan relevan yaitu dengan merancang asesmen literasi kimia. Perancangan asesmen literasi kimia berdasarkan PISA merupakan suatu inovasi dalam bidang pendidikan dan menjadi salah satu solusi dalam melatih literasi sains peserta $\operatorname{didik}^{[10]}$.

\section{METODE}

Jenis penelitian ini adalah pengembangan menggunakan desain Model of Educational Reconstruction (MER). Penelitian ini dilakukan untuk menentukan nilai validitas konten (isi) dan item butir soal, nilai reliabilitas, tingkat kesukaran, dan daya pembeda soal. Instrumen yang digunakan dalam penelitian ini adalah soal literasi kimia. Data validasi yang diperoleh dianalisis menggunakan skala Aiken's V.

$$
V=\frac{\sum s}{n(c-1)}
$$

Keterangan :

$\mathrm{s}=\mathrm{r}-\mathrm{lo}$

lo = angka penilaian validitas yang terendah (misalnya 1)

c = angka penilaian validitas tertinggi (misalnya 5)

$r$ = angka yang diberikan oleh penilai

Kriteria penilaian berdasarkan skala Aiken's V dapat dilihat pada Tabel 1. 
Tabel 1. Validasi berdasarkan skala Aiken's V ${ }^{[1]}$.

\begin{tabular}{c|c} 
Skala Aiken's V & Validitas \\
\hline $\mathrm{V} \leqslant 0,4$ & Kurang \\
\hline $0,4<\mathrm{V} \leqslant 0,8$ & Sedang \\
\hline $0,8<\mathrm{V}$ & Valid
\end{tabular}

\section{HASIL DAN DISKUSI}

\subsection{Hasil}

Perancangan soal literasi menggunakan Model of Educational Reconstruction yang terdiri dari tiga tahap: (1) analisis struktur konten, (2) penyelidikan empiris, dan (3) konstruksi asesmen literasi kimia. Tahapan yang pertama dari Model of Educational Reconstruction (MER) yaitu analisis struktur konten. Tahapan yang dilakukan pada analisis ini yaitu: analisis kurikulum, analisis konten serta analisis konteks. Berdasarkan tahapan tersebut diperoleh hasil berupa:

\subsubsection{Analisis Kurikulum}

Tahap pertama yang dilakukan adalah menganalisis Kompetensi Dasar (KD) pada materi hukum-hukum dasar kimia yaitu KD 3.10 menerapkan hukum-hukum dasar kimia, konsep massa molekul relatif, persamaan kimia, konsep mol, dan kadar zat untuk menyelesaikan perhitungan kimia. KD tersebut dianalisis berdasarkan taksonomi bloom. Pada taksonomi bloom kemampuan berpikir KD 3.10 yaitu menerapkan artinya capaian pembelajaran minimal adalah menerapkan (C3).

\subsubsection{Analisis konten}

Analisis konten merupakan analisis terhadap materi pokok hukum-hukum dasar kimia dan stoikiometri yang dilakukan dengan menggunakan beberapa buku kimia Universitas diantaranya buku Raymond Chang, Petrucci, dan Oxtoby. Analisis ini bertujuan untuk memperoleh konsep yang benar berdasarkan keilmuan sains.

\subsubsection{Analisis konteks}

Analisis konteks dilakukan dengan tujuan memperoleh materi yang berkaitan dengan kehidupan sehari-hari.Analisis konteks ini diperoleh dari beberapa artikel ilmiah. Analisis konteks haruslah sesuai dengan perkembangan teknologi saat ini agar seseorang dapat menghubungkan materi kimia dengan kehidupan sehari-hari sehingga melek akan sains dan teknologi. Salah satu materi pokok pada KD 3.10 yaitu hukum Dalton. Konteks hukum dalton yang dirancang yaitu dampak hujan asam dalam kehidupan berupa pencemaran lingkungan, karena dapat menurunkan populasi ikan, tumbuhan akuatik dan jasad renik. Konteks ini diperoleh dari jurnal LAPAN ${ }^{[12]}$.

\subsubsection{Kisi-kisi soal}

Tahap selanjutnya yaitu pembuatan kisikisi soal literasi kimia. Komponen yang terdapat pada kisi-kisi soal literasi kimia adalah KD, IPK, indikator soal, level kognitif dan level pengetahuan berdasarkan taksonomi bloom, serta aspek literasi kimia. Pembuatan indikator soal disesuaikan dengan indikator pencapaian kompetensi (IPK) berdasarkan level kognitif dan level pengetahuan pada taksonomi bloom.

\subsubsection{Kartu soal}

Pembuatan kartu soal dan pedoman penskoran dirancang berdasarkan beberapa komponen yaitu Kompetensi Dasar (KD), Indikator Pencapaian Kompetensi (IPK), materi, indikator soal, level kognitif, level pengetahuan, level literasi kimia, soal literasi kimia, serta rubrik penilaian soal literasi kimia. Rubrik jawaban soal literasi kimia dirancang berdasarkan level literasi diantaranya scientific illiteracy, nominal scientific literacy, functional scientific literacy, conceptual scientific literacy, dan multidimensional scientific literacy.

\subsubsection{Validitas Konten}

Pada tahapan selanjutnya setelah analisis struktur konten yaitu penyelidikan empiris. Instrumen pengumpulan data uji validitas konten yaitu berupa angket. Angket validitas konten disusun dengan 3 komponen pertanyaan yang terdiri dari wacana soal, pertanyaan, dan rubrik jawaban soal. Untuk penilaian dari 3 komponen tersebut diberi skor 1-5 di mana skor 1 menunjukkan tidak valid, skor 2 kurang valid, skor 3 cukup valid, skor 4 valid, dan skor 5 sangat valid.

Hasil analisis validitas konten ini diolah menggunakan rumus Aiken's V. Berdasarkan hasil penelitian diperoleh nilai validitas konten (V) pada soal literasi kimia sebesar 0,86 pada kategori "valid". Artinya asesmen literasi kimia tersebut sudah dapat mencerminkan keseluruhan konteks maupun konten dan selanjutnya. Tes skala kecil dilakukan untuk menguji validitas item butir soal, reliabilitas tes, indeks kesukaran, dan daya pembeda. Pada tahap uji coba ini sampel yang digunakan sebanyak 72 siswa. Jumlah sampel tersebut diperoleh berdasarkan rumus Slovin yaitu:

$$
\mathrm{n}=\frac{N}{1+N e^{2}}
$$
Keterangan :
$\mathrm{n}=$ ukuran sampel
$\mathrm{N}=$ ukuran populasi
e $=$ persen kelonggaran ketidaktelitian ${ }^{[13]}$.

\subsubsection{Validitas item butir soal}

Untuk menganalisis validitas item butir soal, peneliti menggunakan software ANATES uraian. Berdasarkan hasil yang diperoleh terdapat 3 soal masuk dalam kategori sangat signifikan, 9 soal dengan kategori signifikan, dan 3 soal dengan kategori tidak signifikan. Berikut data analisis validitas item butir soal pada Tabel 2 . 
Tabel 2. Analisis validitas item butir soal.

\begin{tabular}{c|c|c|c} 
No & Signifikansi & $\begin{array}{c}\text { Tingkat } \\
\text { Kesukaran }\end{array}$ & $\begin{array}{c}\text { Daya } \\
\text { Beda }\end{array}$ \\
\hline 1 & Sangat Signifikan & Sedang & Baik \\
\hline 2 & Signifikan & Sedang & Sedang \\
\hline 3 & Signifikan & Sedang & Baik \\
\hline 4 & Sangat Signifikan & Sukar & Sedang \\
\hline 5 & Signifikan & Sedang & Sedang \\
\hline 6 & Sangat Signifikan & Sukar & Sedang \\
\hline 7 & - & Sedang & Sedang \\
\hline 8 & Signifikan & Sedang & Baik \\
\hline 9 & - & Sedang & Jelek \\
\hline 10 & Signifikan & Sukar & Sedang \\
\hline 11 & Signifikan & Sedang & Baik \\
\hline 12 & Signifikan & Sangat & Sedang \\
\hline 13 & Signifikan & Sukar & Sedang \\
\hline 14 & - & Sukar & Jelek \\
\hline 15 & Signifikan & Sukar & Sedang
\end{tabular}

\subsubsection{Reliabilitas Tes}

Pengujian reliabilitas tes bertujuan untuk mengukur seberapa jauh konsistensi skor tersebut dari satu pengukuran ke pengukuran yang lainnya ${ }^{[14]}$. Untuk menganalisis nilai reliabilitas tes dari asesmen ini, peneliti menggunakan software ANATES. Berdasarkan hasil yang diperoleh bahwa nilai reliabilitas tes dari asesmen ini adalah 0,88. Perolehan nilai ini artinya tes tersebut sudah reliabel karena syarat suatu tes dikatakan reliabel harus berada di atas nilai 0,7.

\subsubsection{Tingkat kesukaran soal}

Menganalisis tingkat kesukaran soal artinya mengkaji soal tersebut berdasarkan tingkat kesukaran sehingga diperoleh soal dengan kategori mudah, sedang, dan sukar ${ }^{[15]}$. Tingkat kesukaran soal yang baik adalah soal-soal yang diberikan tidak terlalu sukar dan tidak terlalu mudah ${ }^{[16]}$. Berdasarkan hasil yang diperoleh terdapat 8 soal dengan kategori sedang, 6 soal dengan kategori sukar, dan 1 soal dengan kategori sangat sukar.

\subsubsection{Daya pembeda}

Daya pembeda adalah kemampuan butir soal membedakan peserta didik yang mempunyai kemampuan tinggi dan rendah ${ }^{[16]}$. Tujuan menganalisis daya pembeda yaitu untuk menentukan mampu atau tidaknya suatu soal membedakan peserta didik yang berkemampuan tinggi dengan yang berkemampuan rendah ${ }^{[15]}$. Berdasarkan hasil yang diperoleh terdapat 9 item butir soal dengan kategori sedang, 4 item butir soal dengan kategori baik,dan 2 item butir soal dengan kategori jelek.

\subsection{Pembahasan}

Asesmen literasi kimia dirancang menggunakan MER (Model of Educational Reconstruction) yang terdiri dari 3 tahapan dasar yang dapat dilakukan bolak-balik dan tidak harus berurutan yaitu (1) analisis struktur konten, (2) penyelidikan empiris dan (3) konstruksi pembelajaran $^{[17]}$. Tahapan yang pertama dari Model of Educational Reconstruction (MER) yaitu analisis struktur konten. Tahapan pertama yang dilakukan adalah analisis struktur konten yang terdiri dari analisis kurikulum, analisis konten, dan analisis konteks.

Aspek literasi kimia terdiri dari konten, konteks, HOLS, dan sikap. Konten mencakup pengetahuan yang bersifat ringkas dan jelas yaitu pengetahuan tentang konsep, teori atau fakta-fakta kimia, pengetahuan prosedural seperti keterampilan atau tindakan yang dikuasai dalam memperoleh pengetahuan ilmiah. Konteks mencakup pentingnya ilmu kimia pada fenomena/situasi dalam kehidupan sehari-hari. HOLS mencakup dapat menentukan isu-isu ilmiah serta menjelaskan fenomena/situasi ilmiah. Sikap merupakan aspek yang penting dalam literasi kimia karena menunjukkan ketertarikan peserta didik terhadap isu-isu ilmiah dan rasa tanggung jawab yang dimiliki dalam situasi tersebut.

Tahapan yang kedua dari model MER adalah Studi empiris terhadap pengaturan belajar tertentu yang membutuhkan studi lebih lanjut dengan melakukan investigasi konsepsi pre-instructional siswa dan variabel afektif seperti ketertarikan, konsep diri, dan sikap. Hal tersebut dilakukan dengan tujuan agar perancangan asesmen sesuai dengan kriteria yang semestinya. Selain siswa, pada penyelidikan empiris juga meminta konsepsi guru/ dosen dalam melakukan justifikasi terhadap draft rancangan soal. Proses justifikasi ini disebut dengan validitas konten (isi) oleh judgment expert. Validitas isi ini ditujukan agar dapat menentukan apakah soal berupa wacana soal, pertanyaan soal, serta jawaban soal dalam suatu tes yang dirancang valid artinya mampu mewakili secara keseluruhan konten atau materi yang diujikan.

Klarifikasi materi subjek, dalam hal ini draft rancangan soal menggambarkan analisis konten secara kualitatif terhadap buku teks yang berkualitas dan dari beberapa publikasi artikel serta menentukan apakah tes tersebut sudah valid atau tidaknya. Berdasarkan hasil rekapitulasi analisis validitas 15 butir soal diperoleh 3 soal dengan kategori sangat signifikan, 9 soal dengan kategori signifikan. Ada 3 soal dengan kategori tidak signifikan artinya perlu dilakukan revisi.

Analisis reliabilitas diperoleh yaitu 0,88 artinya tes tersebut sudah reliabel karena syarat suatu tes dikatakan reliabel harus berada di atas nilai 0,7. Selanjutnya menganalisis kesukaran soal. Tingkat kesukaran soal adalah angka yang menunjukkan bahwa apakah soal yang diujikan termasuk mudah, sedang atau sukar. Soal yang baik adalah soal yang tidak terlalu mudah atau tidak terlalu sukar. Analisis tingkat kesukaran tes diperoleh hasil bahwa ada 8 soal dengan kategori sedang, 6 soal pada kategori sukar, dan 1 soal pada kategori sangat sukar. 
Tahapan setelah menganalisis kesukaran soal yaitu analisis daya pembeda. Daya pembeda adalah kemampuan butir soal membedakan peserta didik yang mempunyai kemampuan tinggi dan rendah. Berdasarkan hasil yang diperoleh bahwa daya pembeda dengan kategori sedang sebanyak 9 item butir soal, daya pembeda dengan kategori baik sebanyak 4 item butir soal, dan daya pembeda dengan kategori jelek sebanyak 2 item butir soal. Ada 2 soal dengan kategori jelek. Rancangan soal literasi kimia terdiri atas 7 wacana soal dan 15 butir item soal. Salah satu contoh wacana soal literasi kimia dapat dilihat pada Tabel 3.

Tahapan yang ketiga yaitu konstruksi pembelajaran. Pada tahapan ini dilakukan rekonstruksi ulang terhadap hasil analisis struktur konten dan hasil penyelidikan empiris di mana didapatkan sebanyak 12 butir item soal dalam kategori baik dan benar.

Tabel 3. Rancangan soal literasi kimia.

Wacana antasida obat sakit maag untuk pertanyaan no $1 \mathrm{a}, 1 \mathrm{~b}$.

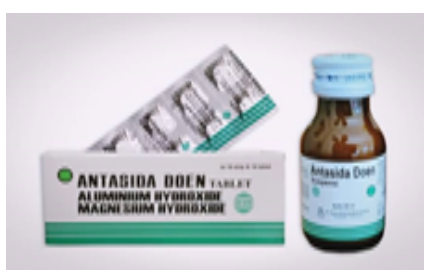

Gambar 1. Antasida obat sakit maag (http//alodokter.com)

Antasida merupakan senyawa yang memiliki kemampuan menetralkan asam lambung di dalam tubuh. Antasida bermanfaat untuk mengobati penyakit saluran cerna karena mengembalikan derajat keasaman lambung pada $\mathrm{pH}$ 3-5.Ada bermacam-macam kombinasi bahan aktif antasida, salah satu bahan baku pembuatan antasida yaitu aluminium atau magnesium yang disebut hydrotalcite. Hydrotalcite $\left(\mathrm{Mg}_{6} \mathrm{Al}_{2}(\mathrm{OH})_{16} \cdot 4 \mathrm{H}_{2} \mathrm{O}\right)$ merupakan salah satu contoh antasida yang memiliki kemampuan lebih baik dibandingkan antasida lainnya dalam menetralisasi asam lambung yang berlebihan. Mekanisme hydrotalcite dalam menetralkan asam lambung/tukak peptik ( $\mathrm{HCl})$ yaitu:

$\mathrm{Mg}_{6} \mathrm{Al}_{2}(\mathrm{OH})_{16} \cdot 4 \mathrm{H}_{2} \mathrm{O}+18 \mathrm{HCl} \rightarrow 6 \mathrm{MgCl}_{2}+2 \mathrm{AlCl}_{3}+21 \mathrm{H}_{2} \mathrm{O}+\mathrm{CO}_{2}$

\section{Pertanyaan}

a. Jika dalam suatu reaksi tersebut diketahui massa total zat-zat hasil reaksi sebanyak 15,6 gram, maka tentukanlah massa hydrotalcite yang dibutuhkan untuk bereaksi dengan 6,8 gram $\mathrm{HCl}$, lengkapi jawaban!

b. Berdasarkan jawaban yang diperoleh, hukum apa yang mendasari reaksi tersebut, berikan alasan!

\section{Analisa Pertanyaan dan Jawaban}

a. Tuntutan indikator soal pada pertanyaan no 1.a yaitu peserta didik dapat menentukan massa hydrotalcite berdasarkan hukum Lavoisier. Tingkatan level literasi kimia yang diukur adalah functional scientific literacy. Functional scientific literacy artinya peserta didik dapat menjawab dengan benar namun pengetahuannya masih sangat terbatas. Adapun tingkatan level literasi kimia yang diukur hanya sampai pada functional scientific literacy karena tuntutan indikator soal yaitu dapat menentukan massa hydrotalcite artinya peserta didik hanya dituntut untuk menetukan massa hydrotalcite berdasarkan mekanisme reaksi pada soal. Nilai validitas item butir soal nomor 1.a yaitu 1,16 artinya dapat dikatakan valid. Berikut jawaban yang dirancang berdasarkan tingkatan level literasi:

- Level literasi sains: Functional scientific literacy.

\section{- Uraian Jawaban:}

$\mathrm{Mg}_{6} \mathrm{Al}_{2}(\mathrm{OH})_{16} \bullet 4 \mathrm{H}_{2} \mathrm{O}+18 \mathrm{HCl} \rightarrow 6 \mathrm{MgCl}_{2}+2 \mathrm{AlCl}_{3}+21 \mathrm{H}_{2} \mathrm{O}+\mathrm{CO}_{2}$

Massa total zat-zat sesudah bereaksi $=6,8 \mathrm{gram}$

Massa hydrotalcite $=$ massa total zat-zat sesudah bereaksi - massa $\mathrm{HCl}$

Massa hydrotalcite $=8,8$ gram

$$
=15,6 \mathrm{gram}-6,8 \mathrm{gram}=8,8 \text { gram }
$$

- Skor: 10.

b. Tuntutan indikator soal pada pertanyaan nomor 1.b yaitu peserta didik dituntut untuk menerapkan hukum Lavoisier. Tingkatan level literasi kimia yang diukur adalah functional scientific literacy. Nilai validitas item butir soal nomor 1.b yang diperoleh yaitu 1,16 artinya dapat dikatakan valid. Berikut jawaban yang dirancang berdasarkan tingkatan level literasi:

- Level literasi sains: Functional scientific literacy.

- Uraian Jawaban:

Berdasarkan jawaban yang diperoleh dari reaksi tersebut berlaku hukum Lavoisier atau hukum kekekalan massa. Hukum Lavoisier mengatakan bahwa massa total zat-zat sebelum bereaksi sama dengan massa total zat-zat sesudah bereaksi.

- Skor: 10. 


\section{SIMPULAN}

Berdasarkan penelitian yang telah dilakukan diperoleh kesimpulan yaitu: Validitas konten (isi) asesmen literasi kimia yang dirancang dikategorikan "valid" dengan nilai 0,86. Validitas butir soal asesmen literasi kimia diperoleh 3 soal dengan kategori sangat signifikan, 9 soal dengan kategori signifikan, dan 3 soal dengan kategori tidak signifikan. Soal dengan kategori tidak signifikan artinya perlu dilakukan revisi. Reliabilitas tes asesmen literasi kimia yang dirancang sudah dikategorikan reliabel dengan nilai 0,88 . Tingkat kesukaran soal ada 8 soal pada kategori sedang, 6 soal pada kategori sukar dan 1 soal pada kategori sangat sukar. Daya pembeda dengan kategori sedang sebanyak 9 item butir soal, daya pembeda dengan kategori baik sebanyak 4 item butir soal, dan daya pembeda dengan kategori jelek sebanyak 2 item butir soal. Sehingga dapat disimpulkan dari 15 rancangan soal, terdapat 12 butir item soal dalam kategori baik dan benar.

\section{REFERENSI}

1. F. U. Lampung, J. Prof, and S. Brojonegoro, "Rahmayani et al. Pengembangan Instrumen Asesmen Kognitif berbasis .... |191,” pp. 191-202.

2. S. Rahayu, "Prosiding Seminar Nasional Kimia UNY 2017 Sinergi Penelitian dan Pembelajaran untuk Mendukung Pengembangan Literasi Kimia pada Era Global Ruang Seminar FMIPA UNY, 14 Oktober 2017," Pros. Semin. Nas. Kim. UNY 2017, pp. 319-324, 2017.

3. Holbrook, J, \& Rannikmae, M. 2009. The Meaning Of Scientific Literacy. International Journal of Environmental \& ScienceEducation, 4(3), 275-288.

4. A. Sujana, "Literasi Kimia Mahasiswa PGSD dan Guru IPA Sekolah Dasar Pada Tema Udara," Mimb. Sekol. Dasar, vol. 1, no. 1, pp. 99-107, 2014.

5. M. Perkasa and N. Aznam, "Pengembangan SSP Kimia Berbasis Pendidikan Berkelanjutan Untuk Meningkatkan Literasi Kimia dan Kesadaran Terhadap Lingkungan,” J. Inov. Pendidik. IPA, vol. 2, no. 1, p. 46, 2016.

6. OECD, "Country note - results from PISA 2015: Indonesia,” Oecd, pp. 1-8, 2016.

7. OECD, "What 15-year-old students in Indonesia know and can do," Program. Int. Student Assess. Result from PISA 2018, pp. 1-10, 2018.

8. A. Ali, I. Ardiansyah, D. Irwandi, and D. Murniati, "Analisis Literasi Sains Siswa Kelas XI IPA Pada Materi Hukum Dasar Kimia di Jakarta Selatan," J. Kim. dan Pendidik., vol. 1, no. 2, pp. 149-161, 2016.

9. Shwartz Y, Ben-Zvi R, Hofstein A. The Use of Scientific Literacy Taxonomy for Assessing The Development of Chemical Literacy Among High-School Students. Chem Educ Res Pract 2006;7(4):203-25.
10. E. Yusmaita and E. Nasra, "Perancangan Assesmen Literasi Kimia Dengan Menggunakan Model of Educational Rekonstruction (MER) Pada Tema: 'Air Sebagai Pelarut Universal,'” J. Eksakta Pendidik., vol. 1, no. 2, p. 49, 2017.

11. Hendryadi. Content Validity (Validitas Isi). Teor Pers Pap 2014;01(01):1-5

12. Cahyono, E. Pengaruh Hujan Asam pada Biotik dan Abiotik. LAPAN 2007;8(3)

13. Imran, A. Peran Sampling dan Distribusi Data Dalam Penelitian Komunikasi Pendekatan Kuantitatif. Jurnal studi komunikasi dan media. Vol.21 No.1 (Januari - Juni) Hal : 111126

14. Khumaedi, M. Reliabilitas Instrumen Penelitian Pendidikan. Vol. 12, No. 1, Juni 2012 (25-30)

15. Bagiyono. Analisis Tingkat Kesukaran dan Daya Pembeda Butir Soal Ujian Pelatihan Radiografi Tingkat 1. Widyanuklida, Vol. 16 No. 1, November 2017: 1 - 12 ISSN 1410-5357

16. Rahayu, Tika D, Purnomo, Bambang $\mathrm{H}$, Sukidin. Analisis Tingkat Kesukaran dan Daya Beda Pada Soal Ujian Tengah Semester Ganjil Bentuk Pilihan Ganda Mata Pelajaran Ekonomi Kelas X di SMA Negeri 5 Jember Tahun Ajaran 2012-2013. Jurnal Edukasi Unej 2014, I (1): 39-43

17. Duit R, Gropengieber H, Kattmann U, Komorek M, Ilka Parchmann. The Model of Educational Reconstruction - A Framework for Improving Teaching and Learning Science. 2009;(1995):1-20.

\section{KOREKSI}

Berdasarkan permintaan Penulis pada Rabu, 09 Juni 2021, terkait kesalahan data pada naskah ini, redaksi telah memperbaiki nilai Validitas Konten (V) pada halaman 130 dan 133, dari sebelumnya $\mathbf{1 , 1 1}$ menjadi $\mathbf{0 , 8 6}$. Atas perhatiannya kami ucapkan terima kasih. 